\title{
Improving the of Thermophysical Characteristics of Heat Pipes
}

\author{
Vladimir A. Kulagin* and Nikita Yu. Sokolov \\ Siberian Federal University \\ 79 Svobodny, Krasnoyarsk, 660041, Russia
}

Received 18.09.2016, received in revised form 29.10.2016, accepted 14.01.2017

Examined new design heat pipes in order to increase maximum flow heat. Presented the methodology for calculating maximum power for heat pipes. Presented the variants of the implementation of highly efficient heat pipes with a maximum the withdrawn power. Presented the possibility to use them as a highly reliable cooling system component of military and civilian equipment.

Keywords: heat pipe, space vehicles, the coolant.

Citation: Kulagin V.A., Sokolov N.Yu. Improving the of thermophysical characteristics of heat pipes, J. Sib. Fed. Univ. Eng. technol., 2017, 10(3), 372-376. DOI: 10.17516/1999-494X-2017-10-3-372-376.

\section{Улучшение теплофизических характеристик тепловых труб}

\author{
В.А. Кулагин, Н.Ю. Соколов \\ Сибирский федеральный университет \\ Россия, 660041, Красноярск, пр. Свободныий, 79
}

Рассмотрена новая конструкиия тепловых труб $l k z$ увеличения максимально отводимого теплового потока. Приведена методика расчета максимально отводимой мошности. Рассмотрены варианты реализации высокоэффективных тепловых труб (ВТТ) с максимально отводимой мощностью. Показана возможность использовать их как высоконадежный элемент системы охлаждения военной и гражданской техники.

Ключевые слова: тепловая труба, космические аппараты, теплоноситель.

\section{Введение}

Перспективы развития информационных спутниковых систем в России связаны с созданием негерметичных космических аппаратов (КА). Такие аппараты уже вошли в состав глобальной навигационной системы ГЛОНАСС. Одновременно идет разработка новых моделей

C) Siberian Federal University. All rights reserved

* Corresponding author E-mail address: v.a.kulagin@mail.ru 
КА с увеличенной мощностью более 15 кВт, сроком активного существования более 15 лет и с повышенными точностными навигационными и временными характеристиками.

Одной из главных проблем на борту КА является обеспечение оптимального теплового режима радиоэлектронной аппаратуры (РЭА). В условиях постоянно возрастающей мощности бортовой аппаратуры и необходимости уменьшения ее объема и массы обеспечение работы КА возможно только за счет увеличения эффективности работы систем отвода тепла. Основной принцип функционирования системы обеспечения теплового режима заключается в поддержании требуемого диапазона температур на посадочных местах тепловыделяющего оборудования космического аппарата КА при заданном энергопотреблении [1, 2]. От этого зависит долговечность и надежность функционирования спутника в целом. Для минимизации массоэнергетических параметров системы целесообразно использовать принцип естественной, нерегулируемой передачи тепловой мощности с более высокого температурного уровня на низкий. Наиболее предпочтительным средством реализации этого принципа являются тепловые трубы (ТT), работающие на основе замкнутого испарительно-конденсационного цикла. ТТ отличаются высокой эффективной теплопроводностью, в десятки раз превышающей теплопроводность металлов. Это позволяет оптимально решать многие инженерные задачи, связанные с передачей тепла с минимальными потерями, охлаждением и термостатированием или термостабилизацией различных объектов, использующихся как на Земле, так и в космическом пространстве.

Современные искусственные спутники Земли для связи и телерадиовещания представляют собой КА, оснащенные крупногабаритным негерметичным приборным отсеком в виде блочно-модульной конструкции на основе плоских прямоугольных сотовых панелей [3], несущих на себе теплонагруженные приборы радиоэлектронной бортовой аппаратуры (БА) [4].

Отсутствие в конструкциях ТТ движущихся механических частей, использование для движения теплоносителя капиллярных сил, высокая плотность передаваемого теплового потока при минимальных перепадах температур (термических сопротивлениях) и автономность работы каждой из них, возможность резервирования, минимальное обслуживание и малый удельный вес, бесшумная работа создают им преимущества и обеспечивают надежность и долговечность перед иными способами термостатирования заданного объекта на борту КА. Панели с вмонтированными в них ТТ - надежная защита от ударов микрометеоритов [5]. Изотермализирующая природа ТТ уменьшает температуры мощных компонентов тепловыделяющего оборудования, увеличивая таким образом надёжность их работы.

\section{Методика расчета массогабаритных характеристик TT}

Разница в давлении между жидкой и газообразной фазами теплоносителя в каждой точке тепловой трубы не должна превышать величины капиллярного напора, который способна развивать пористая структура $[6,7]$.

Новая математическая модель представлена уравнениями (1-8), состоит из уравнений Дарси для жидкой фазы теплоносителя (1-4), уравнений оптимизации массогабаритных характеристик ТТ (5-7) и уравнения для газовой фазы теплоносителя (8):

$$
-373-
$$




$$
\begin{aligned}
& \Delta P_{l}=\frac{\mu_{l} l Q}{K S \rho_{l} \lambda}, \\
& \Delta P_{c}=\frac{2 \sigma \cos \varphi}{r_{c}}, \\
& \Delta P_{g}=\rho_{l} g l \sin \varphi, \\
& \Delta P_{c}=\Delta P_{l}+\Delta P_{g}, \\
& m=n \rho_{f} S l, \\
& \frac{m}{Q}=K r, \\
& \left\{\begin{array}{c}
K r \geq 2 n, \quad l=\frac{l_{0}}{n}+\frac{Q}{P_{\text {specific }} \cdot B}, \quad n=2,3,4 \ldots \\
K r \leq 2 n, \quad l=l_{0}, \quad n=1,
\end{array}\right. \\
& d_{v}=\sqrt{\frac{20 Q}{\pi \rho_{v} \lambda \sqrt{\gamma_{v} R_{v} T_{v}}}},
\end{aligned}
$$

где $\mu_{l}$ - вязкость жидкости; $l_{0}$ - длина ТТ; $Q$ - мощность источника тепла; $K$ - проницаемость фитиля; $\rho_{l}$ - плотность жидкости; $S$ - площадь поперечного сечения фитиля; $\lambda$ - теплота парообразования; $\sigma$ - поверхностное натяжение; $r_{c}$ - радиус капилляров; $\varphi$ - угол наклона ТТ; $\mathrm{g}$ - ускорение свободного падения; $\rho_{a}-$ плотность фитиля; $n$ - количество ТТ в системе (количество перегородок равно $=n-1) ; P_{\text {specific }}-$ максимальный удельный тепловой поток (УТП) через перегородку (ограничение по кипению ТТ); $K r$ - критерий масса/мощность; $B$ - ширина ТT; $\rho_{v}-$ плотность фитиля; $R_{v}$ - газовая постоянная; $d_{v}-$ диаметр газового канала.

Физический смысл математической модели заключается в объединении массогабаритных и теплофизических характеристик ТТ. Для обеспечения отвода теплового потока (по критерию «капиллярное осушение») с увеличением длины ТТ требуется увеличение поперечной площади фитиля ТТ и нелинейной зависимости. Критерий $K r$ определяет отношение массы к мощности ТТ, при превышении которого следует преобразовать одну ТТ в $n$-труб и установить между ними связь (сделать общих $n$-1 перегородок).

Критерий $K r$ определен уровнем техники, т.е. первоначально получен из соотношения для медной ГТПС, которая при весе 180 г способна отводить 40 Вт вертикально (в условиях гравитации) с высоты 160 мм (25 мм зона конденсации), $K r=4,5$ г/Вт. Данный критерий путем анализа результатов расчета по новой математической модели для современных ТТ был принят равным 2 г/Вт (с критерием 4,5 г/Вт при добавлении перегородки резко уменьшалась масса системы), что обеспечивает достаточно плавный переход по весу ТТ в зависимости от мощности. Перепад температуры в зоне конденсации определен теплопроводностью конструкционного материала (стенки и фитиль сделаны из одного материала), теплопроводности жидкости и УТП. Значение перепада должно быть меньше $1-2{ }^{\circ} \mathrm{C}$, для меди при площади перегородки $10 \mathrm{~cm}^{2}$ составит $1,2^{\circ} \mathrm{C}$. Внешний вид новой ТТ и детализация перегородки представлены на рис. 1 и 2. Сборка ТТ названа высокоэффективной тепловой трубой (ВТТ). ВТТ будет обладать по- 


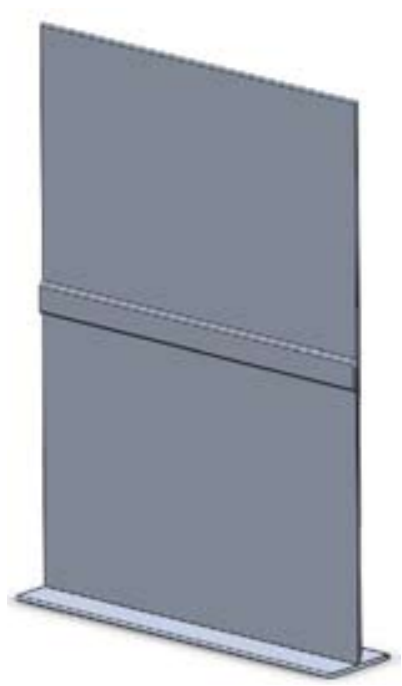

Рис. 1. Внешний вид ВТТ

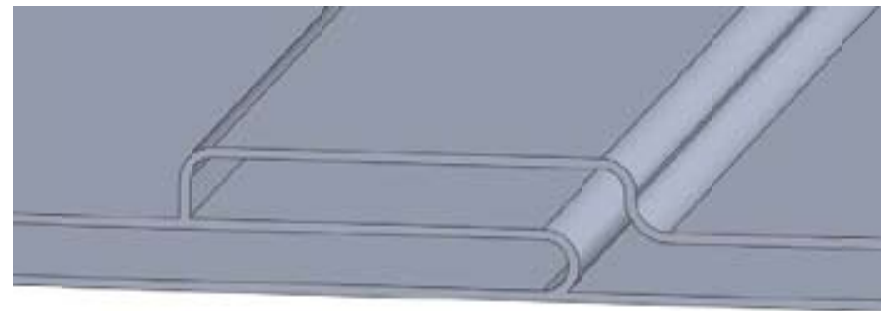

Рис. 2. Перегородка ВТТ

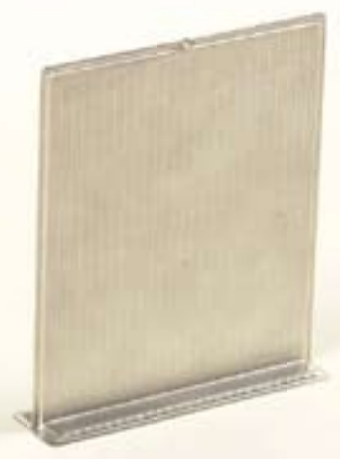

a)

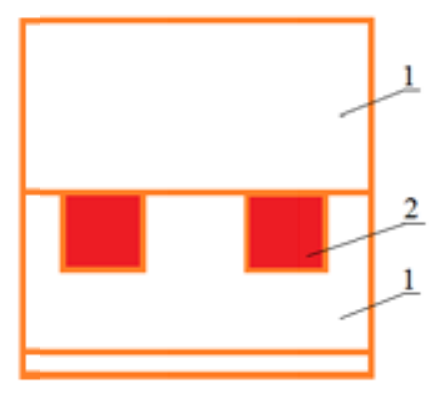

Зона конденсации

б)

Рис. 3. Внешний вид ГТПС (а); зоны унифицированной ВТТ (б): 1 - ВТТ с периметром 0,4 м; 2 - ВТТ с периметром 0,16 м

добными ГТПС теплофизическими характеристиками (разница температур между зоной испарения и конденсации менее $3{ }^{\circ} \mathrm{C}$ ), при этом толщина ВТТ составит 1,4 мм, а масса по сравнению с медной ГТПС уменьшится на 30-40 \%.

На рис. 3 схематично реализован принцип унифицированной ВТТ. Имеются сегменты 2 (рис. 3) с периметром 0,16 м, в которые возможно установить радиоэлементы с УТП более $30 \mathrm{BT} / \mathrm{cm}^{2}$.

Принципиально новый подход к конструкции ТТ даёт возможность применять их как высоконадежный элемент системы охлаждения военной и гражданской техники. Система охлаждения может быть собрана с использованием исключительно ВТТ.

Исследование выполнено при финансовой поддержке Российского фонда фундаментальных исследований, Правительства Красноярского края, Красноярского краевого фон- 
да поддержки научной и научно-технической деятельности в рамках научного проекта № 16-41-242156 p_oфu_m

\section{Список литературы}

[1] Кулагин В.А., Соколов Н.Ю. Разработка оборудования для тестирования тепловых труб, Журнал СФУ. Техника и технологии, 2015, 8(6), 774-785: DOI: 10.17516/1999-494X-2015-8-6-774785 [Kulagin V.A., Sokolov N.Y. Development of equipment for testing heat pipes J. Sib. Fed. Univ. Eng. technol., 2015, 8 (6), 774-785; DOI: 10.17516/1999-494X-2015-8-6-774-785 (in Russian)].

[2] Деревянко В.А., Нестеров Д.А., Косенко В.Е. и др. Вестник СибГАУ, 2013, 6(52), 111116 [Derevianko V.A., Nesterov D.A., Kosenko V.E. et al. Vestnik SibSAU, 2013, 6(52), 111-116 (in Russian)].

[3] Лукс А.Л., Матвеев А.Г. Вестник СамГУ. Естественнонаучная серия, 2008, 3(62), 331 356 [Lux A.L., Matveev A.G., Vestnik of SSU. The natural science series, 2008, 3(62), 331-356 (in Russian)]

[4] Козулин И.А. Автореф. дис. ... канд. физ.-мат. наук. Новосибирск, 2013. 23 с. [Kozulin I.A. Author. Dis. ... Cand. Sci. Sciences. Novosibirsk, 2013. 23 p. (in Russian)]

[5] Чи С. Тепловые трубы: Теория и практика; пер. с англ. В.Я. Сидорова, 1981. 207 с. [Chi S. Heat pipes: Theory and Practice; Trans. from English. V.Y. Sidorov, 1981. 207 p. (in Russian)].

[6] Кулагин В.А., Соколов Н.Ю. Численное исследование характеристик тепловых труб в составе радиоэлектронного оборудования космических аппаратов. Журнал СФУ. Техника и технологии, 2015, 8(6), 769-773. DOI: 10.17516/1999-494X-2015-8-6-769-773 [Kulagin V.A., Sokolov N.Y. Numerical study of the characteristics of heat pipes as part of electronic equipment of space vehicles. J. Sib. Fed. Univ. Eng. technol., 2015, 8(6), 769-773 DOI: 10.17516/1999-494X-2015-8-6-769773.6 (in Russian)]

[7] Кузнецов Г.В. Санду С.Ф. Теплофизика и аэромеханика, 1998, 5(3), 469-477. [Kuznetsov G.V. Sandu S.F. Thermophysics and Aeromechanics, 1998, 5(3), 469-477 (in Russian)] 